\title{
O campo temático das ciências sociais em saúde no Brasil
}

\author{
Aurea Maria Zöllner lanni
}

Introdução

A história da interlocução das ciências sociais e a saúde não é recente no Brasil, e data das primeiras décadas do século XX; porém, como campo científico (Bordieu, 2013), com circunscrição de objetos próprios e esforços de sistematização normativos e vinculantes, sim. No caso brasileiro, como na América Latina, somente a partir da década de 1970 as ciências sociais tomam a si os objetos de saúde-doença (Briceño-León, 2003, p. 38). Essa é, portanto, uma história de curta duração, e "tal proximidade entre os extremos temporais faz com que qualquer tentativa de construir uma narrativa genética seja, ainda, marcada por certa confusão" (Lessa, 2010, p. 17).

Entretanto, apesar do pouco tempo de institucionalização como campo científico, as ciências sociais em saúde no Brasil têm sido objeto de exercícios permanentes de reconstrução histórica estabelecidos desde a sua gênese. Isso talvez advenha do fato de que, intrinsecamente interdisciplinar, esse campo tenha exigido de seus protagonistas um esforço de identificar a trama produzida por trajetórias institucionais tão diversas, além dos diferentes exercícios de constituição do seu objeto.

A obra de Everardo Duarte Nunes (1985, 1992, 1999, 2006, 2014) tem sido um desses exercícios perenes de construção e (re)construção de narrativa genética. Sociólogo de formação e vinculado ao Departamento de Medicina 
Social da Faculdade de Ciências Médicas da Universidade de Campinas, desde a década de 1960 Nunes sistematiza e analisa a produção científica brasileira do campo das ciências sociais em saúde. Ana Maria Canesqui (1995, 1997, 2007, 2008), da mesma instituição, também tem se dedicado a essa reconstrução, com trabalhos de referência no assunto. As obras de Cohn (1980), Teixeira (1995), Gerschman (1995) e Escorel (1999) sobre a reforma sanitária no Brasil são outros exemplos.

Mais recentemente, pesquisadores vêm se dedicando a essa retrospectiva genética; de forma mais ou menos sistemática, segundo diferentes perspectivas teóricas e enfoques temáticos, ou delineando as diferentes conformações institucionais do campo e a atuação dos seus sujeitos. Grande parte desses trabalhos está publicada em revistas científicas como Saúde e Sociedade, Ciência \& Saúde Coletiva, Cadernos de Saúde Pública, Physis - Revista de Saúde Coletiva, Interface-Comunicação, Saúde, Educação, a revista do Cebes e História, Ciências, Saúde-Manguinhos, entre outras. Há, ainda, uma já significativa produção de dissertações e teses vinculadas aos programas de pós-graduação da área.

A maioria desses trabalhos analisa as configurações institucionais e os sujeitos envolvidos, as linhas de pesquisa dos programas de pós-graduação, os grupos de pesquisa constituídos, as principais instituições formadoras e de pesquisa; identifica também as temáticas predominantes na produção nacional e as principais abordagens metodológicas utilizadas. E já está disponível, ainda, uma produção sobre a periodização do campo, as fases iniciais de conexão das ciências sociais com a saúde desde o início do século XX e os desenvolvimentos posteriores, enfatizando-se o período pós-anos de 1970 (Minayo, 1994e 2013; Goldenberg et al., 2003; Minayo e Coimbra, 2005; Almeida, 2011; Deslandes e Iriart, 2012; Loyola, 2012). No que se refere à presença de cientistas sociais na rede de serviços de saúde, os estudos são muito recentes.

Essa produção parece querer "moldar a sua própria posição e firmar valor de sua contribuição para a história intelectual” (Miceli, 1989, p. 8), provavelmente por dois motivos fundamentais. Ao se constituírem ao largo das escolas de ciências sociais institucionalizadas no país, ocupando-se de um objeto ali pouco discutido ou mesmo inexistente - a saúde -, as ciências sociais em saúde enfrentaram o desafio de afirmar-se, à distância, perante seus pares genéticos, os cientistas sociais “típicos”. Essa posição intrínseca de situar-se fora do lugar talvez tenha estimulado o desejo das ciências sociais em saúde de sistematizar e analisar seus próprios temas e as matrizes teóricas adotadas, bem como seu esforço de moldar sua própria posição. E, perante as disciplinas das ciências naturais, constitutivas e hegemônicas na saúde, as ciências sociais estabelecem- 
-se em um cenário de disputas por sua própria validação, seja pelas proposições teórico-metodológicas, seja pela disputa do objeto saúde em si, diferentemente concebido por elas. Desse embate resultaram, e ainda resultam, os vários estudos sobre a pertinência das abordagens sociais para a compreensão dos processos em saúde-doença e a reafirmação da sua especificidade com relação aos métodos de investigação e análise.

Isso significa que as ciências sociais em saúde como campo científico enfrentaram desde a sua constituição conflitos endógenos e exógenos, tensões latentes e manifestas, o que talvez tenha estimulado o olhar reflexivo desde sempre, em uma narrativa genética simultânea à sua emergência.

Partindo-se do pressuposto de que esse campo se configurou e desenvolveu, em larga medida, paralelamente às ciências sociais institucionalizadas no país (Marsiglia et al., 2003; Canesqui, 2007; Sarti, 2010; Ianni, 2011a; Nunes, 2014), cabem ainda algumas considerações que não pretendem ser exaustivas quanto aos aspectos todos aí intervenientes.

O relativo apartamento desse campo foi produzido por aspectos histórico-conjunturais, como a reestruturação do ensino médico na América Latina e no Brasil nos anos de 1950, que incorporou as ciências sociais nessas graduações, sob impulso e iniciativa da Organização Panamericana de Saúde (Opas) ${ }^{1}$. Houve também a (re)estruturação do sistema de pós-graduação no país a partir dos anos de 1960, que integrou cientistas sociais ao ensino e à pesquisa em saúde; e, ainda, a inserção desses profissionais nos serviços de saúde-escola a partir dos anos de 1970, além da atuação nos serviços de saúde pública no país. Tudo isso em um contexto de luta social pela redemocratização.

No bojo dessas questões conjunturais desenvolveu-se uma produção de conhecimento específica, voltada a discussões teóricas sobre o objeto saúde. A contribuição das ciências sociais foi decisiva, em um cenário marcadamente interdisciplinar, e resultou na formulação do conceito da determinação social do processo saúde-doença, que envolve a ideia da etiologia social dos fenômenos de saúde-enfermidade.

O campo das ciências sociais em saúde é vasto e complexo, e este trabalho pretende explorar, menos do que os aspectos conjunturais da sua constituição, alguns dos aspectos teóricos envolvidos na concepção de saúde formulada. É justamente nesse aspecto, ainda pouco problematizado na bibliografia do/ sobre o campo, que repousa a singularidade da contribuição das ciências sociais à saúde, a singularidade do campo das ciências sociais em saúde no Brasil.

As ciências sociais, ao serem convocadas pelos profissionais da saúde, especialmente os educadores médicos, entraram em contato com um objeto até
1. A Organização Panamericana de Saúde (Opas) data de 1902, e é o primeiro organismo de cooperação internacional em saúde. Em 1947, quando da criação da Organização Mundial de Saúde (oms), ela se integra como escritório regional e como organismo técnico especializado à Organização dos Estados Americanos (OEA), vinculando-se à Organização das Nações Unidas (ONU). Sua função é contribuir para a melhoria de políticas e serviços públicos de saúde por meio da transferência de tecnologia e da difusão do conhecimento.

junho $2015 \quad \mathbf{1 5}$ 
2. Há outras importantes contribuiçōes das ciências sociais à saúde. Ao problematizar o acesso aos serviços de saúde, formulou-se entre os anos de 1970 e 1980 o projeto da Reforma Sanitária, em estreito diálogo com a ciência política. O tema da participação popular é outra contribuição importante, pois introduz essa forma política no aparelho do Estado, impulsionando questões teóricas e práticas. Tais contribuições, entretanto, não serão objeto deste trabalho. então praticamente ausente no ensino de ciências sociais institucionalizado no país. Ainda que a temática da saúde não fosse inusitada aos estudos da área - na sociologia, na antropologia, na política e até mesmo na história, na geografia e nas demais disciplinas -, as abordagens predominantes referiam-se principalmente às culturas das populações indígenas e tradicionais rurais; aos estudos de história social em que algumas epidemias eram descritas; à educação sanitária; e à relação da medicina popular com a medicina científica (Nunes, 2014). A saúde, como objeto, em si era praticamente imperceptível às ciências sociais institucionalizadas. Há exceções. A obra de Bastide (1967) sobre as doenças mentais como objeto sociológico é uma delas, e, apesar da sua proeminência na Faculdade de Filosofia, Ciências e Letras da Universidade de São Paulo, não se consolidou como linha de pesquisa. Há também o livro de Gilberto Freyre (2009), publicado em primeira edição em 1967 na Itália e somente em 2004 no Brasil, sobre sociologia da medicina, que corresponde em muito à sociologia médica que se desenvolvia nos Estados Unidos desde os anos de 1950, de base institucional-comportamental.

Assim, ao voltarem-se para a saúde como um objeto em si, os cientistas sociais enfrentaram duas questões de natureza epistemológica pouco exploradas até então nos cursos de ciências sociais no Brasil: as relações do biológico e do social e a mediação tecnológica na produção dos fenômenos em saúde-doença ${ }^{2}$. Temas que, à época, não haviam ganhado a preeminência atual. Em simpósio sobre o pensamento social brasileiro, Luiz Werneck Vianna (Schwarcz e Botelho, 2011, p. 141) diz que, apesar da diversidade de temas atualmente existentes, "persiste entre eles uma difundida e sempre renovada orientação no sentido de investigar as condições particulares que presidiram a revolução burguesa no Brasil”, e Glaucia Villas Bôas (Idem, p. 140) menciona "problemas recorrentes no conjunto das pesquisas que dizem respeito à identidade nacional e ao desenvolvimento moderno da sociedade brasileira", ressaltando que "há também estudos sobre a institucionalização das ciências sociais [...]”. Nesse mesmo evento, Maria Arminda do Nascimento Arruda (Idem, p. 141) reconhece tanto a diversidade atual de assuntos e abordagens como a persistência das "interpretações sobre o Brasil”. Isso indica o quanto a saúde ainda é pouco presente na área, sugerindo a frágil percepção dos processos sociais envolvidos na produção da saúde e seus fenômenos correlatos, que produzem identidades, culturas, relações produtivas, econômicas, conformações políticas de diferentes ordens etc. É possível dizer, então, que as ciências sociais em saúde se configuram - quanto ao seu objeto e como campo científico - em um cenário de tensões e disputas de diferentes ordens, premidas pela urgência das questões de saúde. 
João Arriscado Nunes (2005, p. 5) analisa o universo das ciências sociais e fala de quão recentes são as pesquisas de temas ligados à saúde, identificando contribuições inovadoras nos seguintes eixos: "biomedicalização, biossociedade e biopoder, a 'velha' e a 'nova' saúde pública; o público e o privado; ação coletiva e participação; saúde e direitos humanos”. Tavares-dos-Santos e Baumgarten (2005), ao apresentarem as contribuições da sociologia na América Latina, mencionam algumas questões que expressariam as profundas transformações das sociedades contemporâneas. Discutindo os novos agentes e lutas sociais e a emergência de novos processos sociais no século XXI, citam a saúde como uma das dimensões fundamentais do processo de globalização, segundo eles caracterizado por profundas desigualdades sociais. Também reconhecem o tema da ciência e da tecnologia - a tecnociência - como estratégico, por constituir força produtiva, o que mereceria atenção criteriosa dos estudiosos da área. Referem, ainda, a problemática do social e do natural, que vem sendo retomada diante dos desafios postos à sustentabilidade ecológica mundial. Para eles, o cenário de globalização da sociedade contemporânea e da mundialização do conhecimento sociológico consiste em "um vasto campo de interrogações à prática sociológica” (Idem, p. 221).

É nesse contexto que a referência a Donnangelo, uma das pioneiras do campo das ciências sociais em saúde no Brasil, ganha relevância. Apresentando uma das primeiras publicações sobre questões históricas e teóricas relativas à saúde, ela fala da importância de estudos dessa natureza pelo seu saldo positivo,

[...] representado não apenas por uma produção acadêmica quantitativa e qualitativamente satisfatória, mas também pela presença de movimentos sociais relacionados à questão da medicina e da saúde sustentados quer por profissionais da área médica, quer por outros segmentos da população. Tal desenvolvimento, contudo, ainda se encontra relativamente restrito a alguns centros de produção intelectual e a algumas áreas do país. Essa limitação, obviamente, não decorre apenas da maior ou menor disponibilidade de bibliografia; mas a possibilidade de acesso às questões que orientam a construção do campo da medicina social é de grande importância para o avanço, no conjunto do país, do debate político sobre a saúde (Donnangelo, 1983, p. 9).

Tomar a saúde como objeto, dedicando-se a questões de cunho teórico pouco exploradas até então pelas ciências sociais no Brasil, indica a radicalidade dessa iniciativa em meados dos anos de 1970, de certa forma anunciando uma “perspectiva crítica, não dogmática e aberta” - emprestando-se aqui os termos 
de Velho (cf. Reis, 1997, p. 22) - e, talvez, também ao que Reis aponta sobre a atual produção das ciências sociais no Brasil:

[... a a grande perplexidade do momento é acrescida pelo fato de que muitos dos termos, dos conceitos fundantes das ciências sociais, perderam sua centralidade ou passaram a competir com uma série de outros na estruturação das próprias disciplinas. Assim, assistimos a uma grande disputa no interior dessas ciências sociais, disputa que é tanto intelectual quanto institucional (Idem, p. 1).

\section{A saúde coletiva e o campo das ciências sociais em saúde}

As ciências sociais em saúde no Brasil, como campo científico, integram o campo ampliado da saúde coletiva que se estruturou formalmente na década de 1970 (Berlinguer et al., 1988; Costa, 1992). Anteriormente à emergência da saúde coletiva, no entanto, existiram interações entre as ciências sociais e a saúde. Cientistas sociais norte-americanos, especialmente alguns antropólogos, como Charles Wagley e Kalervo Oberg, atuaram no Brasil e na América Latina desde o fim dos anos de 1930 e desenvolveram trabalhos em comunidades rurais e indígenas. Na década de 1940, indicando grande interesse pela situação de saúde na região, são estabelecidos convênios bilaterias entre o governo dos Estados Unidos e diversos países latino-americanos, entre eles o Brasil, para melhorar as condições de saúde das populações, atender às exigências das forças armadas aliadas norte-americanas estabelecidas nesses territórios e desenvolver programas de saneamento; o objetivo era demonstrar os benefícios tangíveis da democracia na região (Nunes, 1992). Os anos de 1950 foram os da consolidação da Guerra Fria, em que os Estados Unidos se voltam para a expansão do desenvolvimento capitalista nas Américas, em uma estratégia político-econômica imperialista. A fim de estimular o desenvolvimento latino-americano, diferentes fundações norte-americanas, já atuantes na região, como a Ford, a Kellogg, a Milbank e o Ponto IV, propulsionam sua atuação em vários países, diretamente ou em convênios com a Opas. Elas operam especialmente na atenção materno-infantil, na nutrição e na educação sanitária, áreas consideradas estratégicas para um certo padrão de bem-estar social nos países subdesenvolvidos e, além disso, uma forma de controle e domínio hegemônico sobre o território latino-americano. Foi nesse contexto que se estabeleceu a proposta de reforma do ensino médico.

A reforma do ensino médico na América Latina foi conduzida sob o argumento da modernização e qualificação profissional, pois era conside- 
rado obsoleto e formador de um profissional pouco permeável às crescentes inovações da área médica, que nesse período passava por intenso desenvolvimento tecnológico, característico do capitalismo ocidental pós-Segunda Guerra. Desenvolve-se, então, um ensino voltado para a atenção do indivíduo e da família - garantia da manutenção da força de trabalho e de sua reprodução -, com vistas a um padrão populacional apto à sua incorporação ao mercado de trabalho industrial emergente na região e esteio da expansão do mercado consumidor nas Américas. Esse modelo foi o da medicina comunitária, com enfoque biopsicossocial, uma medicina integral, curativa e reabilitadora, que propunha a participação dos profissionais na solução dos problemas de saúde das comunidades. Tratava-se de uma perspectiva mais social se comparada aos conteúdos estritamente biológicos do ensino médico vigentes até então (Nunes, 1999).

No Brasil e na América Latina esse processo foi reproduzido nos serviços de saúde da atenção primária e nas escolas médicas, por meio da reformulação de seus conteúdos curriculares (Canesqui, 2008), quando foram introduzidos no ensino médico os conteúdos de várias das disciplinas sociais, como os da antropologia, da pedagogia e de certas correntes sociológicas, especialmente de base funcionalista, comportamental, que se encaixavam perfeitamente àquelas diretrizes (Nunes, 1985).

Nos anos de 1960, contudo, ganha força um movimento de questionamento a essa estratégia de ensino e formação, desencadeado por médicos e sanitaristas latino-americanos. A presença de Juan César García na Opas - sanitarista vinculado às causas sociais da América Latina - foi decisiva. Ele estimulou esse debate, envolvendo, especialmente, gente do Brasil, do México, da Bolívia, da Colômbia, entre outros países (Garcia, 1985).

Enquanto esteve na Opas, de 1960 a 1970, Garcia promoveu grande uma transformação na área, acolhendo o potencial contra-hegemônico desse pensamento em saúde que se ia desenvolvendo entre os profissionais latino-americanos. Muitos deles enfrentavam em seus países processos de reformas sociais profundas, enquanto outros enfrentavam lutas democráticas de resistência a golpes militares. Em uma crítica à concepção de social constitutiva do modelo preventivista ${ }^{3}$ (Arouca, 2003), considerada externa às condições sociais de produção de vida - o meio como social, e não as relaçóes produtivas como estruturadoras e constitutivas dos processos de saúde-doença-, desenvolveu-se um movimento de bases teórico-políticas ancorado no materialismo dialético. Discussões sobre a natureza social da medicina foram então intensamente retomadas, revisitando-se as ciências sociais.
3. O termo preventivista refere-se à medicina preventiva, especialidade médica baseada no modelo da história natural da doença proposto por Leavell e Clark (1965). 
No Brasil, esse processo desdobrou-se em dois movimentos conexos: o da reforma sanitária, de marcada natureza política, voltado à discussão e à proposição de um sistema único de saúde no país; e a estruturação do campo da saúde coletiva, voltado para a atuação no âmbito da pesquisa e da formação em saúde, principalmente em nível de pós-graduação. Do primeiro movimento resultou, entre outras iniciativas, o protagonismo na VIII Conferência Nacional de Saúde de 1986, que aprovou a tese da saúde como direito universal no país, mais tarde promulgada na Constituição de 1988 e implantada no Sistema Único de Saúde pela Lei n. 8.080/1990. Com o segundo movimento, criou-se a Associação Brasileira de Pós-Graduação em Saúde Coletiva (Abrasco), fundada em 1979, que se estruturou em três grandes áreas: epidemiologia; política, planejamento e gestão em saúde; e ciências sociais em saúde (Teixeira, 1985; Nunes 1985 e 1999; Canesqui, 1995; Escorel, 1999).

Esse campo constitui um conjunto heterogêneo de sujeitos e atores em torno de ações técnico-científicas e político-institucionais diversas. Como qualquer campo de conhecimentos e de práticas, encontra-se, desde a origem, em permanente movimento, sendo atravessado por profundas tensões de ordem epistemológica, de natureza político-ideológica e por intervenções práticas. Ainda que houvesse divergências teóricas e epistemológicas, decorrentes das disputas entre as várias disciplinas e atores institucionais envolvidos, prevaleceu o que se caracteriza como uma formulação de corte totalizante, mais focada na saúde como questão social e política. A determinação social do processo saúde-doença foi, nesse contexto, o conceito possível, produzido no bojo desse processo (Ianni, 2011b). Por meio dessa formulação pôde-se incorporar o social para além das manifestações estritamente orgânicas do adoecer e articular os fenômenos de saúde e doença ao momento histórico, às alterações políticas, econômicas e sociais do país, abrindo assim canais de influência no plano das práticas e políticas de saúde no país.

O presente trabalho se refere a este universo - o campo da saúde coletiva no Brasil - e, nele, o das ciências sociais em saúde.

\section{Questões teóricas: o objeto saúde em disputa}

Preocupados com a relação saúde-sociedade, os sujeitos do campo da saúde coletiva desenvolvem uma crítica ao objeto saúde vigente no ensino médico, de matriz preventivista, que vê a doença como manifestação estritamente biológica no corpo individual e a sociedade como o meio que deve ser higienizado e normalizado, preventivamente. Orientam-se pela determinação estrutural dos 
processos produtivos que conformam as dinâmicas socioeconômicas e políticas e que consistem nos elementos determinantes da produção dos processos em saúde-doença. O grande substrato dessa reflexão é a desigualdade em saúde no país, que expressaria as situações de classe e a disparidade de acesso aos serviços.

Atualmente existe no campo certo acúmulo autocrítico sobre os limites e as possibilidades dessa abordagem de matriz materialista-histórica de base estruturalista (Cohn, 1992; Bodstein, 1992; Canesqui, 1995; Ianni, 2011a). No entanto, é importante reconhecer que foi essa perspectiva que permitiu a conversão crítica do objeto saúde à época, até então visto predominantemente de forma naturalizada ou biologizada. Assim, o elemento social invadiu o biológico, de matriz biomédica, em um esforço teórico bastante inovador. É nesse cenário que serão abordadas as relações do biológico e do social e as mediações tecnológicas da prática médica.

Para fins de discussão, neste trabalho serão consideradas particularmente as obras dos sociólogos Maria Cecília de Ferro Donnagelo e José Carlos Pereira, ambos de departamentos de medicina preventiva de escolas médicas da Universidade de São Paulo; ela do campus São Paulo, ele do de Ribeirão Preto. Eles não serão os únicos a contribuir com esse debate teórico. Há trabalhos como os de Luz (1979, 1982, 1988), autora consistente e emblemática, ou, ainda, a produção teórica da epidemiologia social, que, ao se debruçar sobre a determinação social do processo saúde-doença, incorporou as ciências sociais (Costa, 1990), sem falar das muitas contribuições de autores diversos, publicadas isoladamente ou nas revistas da área.

\section{O biológico e o social}

A origem das ciências modernas envolveu a busca de leis universais e a reafirmação do dualismo cartesiano, que teve como pressuposto a "distinção fundamental entre natureza e os seres humanos, entre a matéria e a mente, entre o mundo físico e o mundo social/espiritual" (Comissão Gulbenkian, 1996, p. 15). Não seria difícil supor, portanto, o apartamento das ciências sociais no trato dos objetos da natureza - os fenômenos em saúde-doença entre eles -, atribuídos às ciências biológicas por serem relativos aos corpos dos indivíduos e suas manifestações físicas, morfológicas, anatomopatológicas. A saúde é considerada, então, um objeto de possibilidades intrínsecas pouco permeáveis aos pressupostos analíticos e explicativos das ciências sociais. A par dos fenômenos da natureza, as ciências sociais delegaram-nos, como objetos, às ciências naturais, reservando a si os objetos sociais para sua análise e interpretação. 
4. Essa expressão está remetida a Talcott Parsons, que no livro The social system, publicado em 1951, discute o papel social do doente nos sistemas sociais e institucionais.
Tendo em vista que o saber médico e de profissões correlatas é um saber aplicado (Camargo Jr., 2003), não foi diferente. O biológico e o social presentes nesse campo são caudatários dessa ruptura epistemológica disciplinar de tradição moderna.

O esforço teórico, de matriz materialista-histórica, produzido na década de 1970, teve suas bases estruturadas sobre o questionamento do biológico compreendido na estrita acepção da funcionalidade dos órgãos nos corpos dos indivíduos; um biológico "individualizado", desvinculado do coletivo em contexto social. "Ora, saúde e doença são objetos ao mesmo tempo sociais e biológicos”, afirmou Pereira (1986, p. 29), e “os homens são sadios, enfermam e morrem não segundo apenas variáveis biológicas, mas por razões, o mais das vezes, sociais".

A análise do autor parte do pressuposto de que a assistência médica é um objeto de estudo das ciências sociais, referindo-se às abordagens de matriz funcionalista parsoniana ${ }^{4}$, comportamental, dedicada às relações médico-paciente e às instituições hospitalares (Nunes, 1999, p. 123). Ou seja, ele reconhece que a assistência médico-clínica é uma instituição social que tem "a especificidade de se construir de um complexo de ações e relações sociais referidas à área médica" (Pereira, 1986, p. 29). O objeto saúde teria assim a preeminência da clínica médica, o que lhe permite argumentar que a raiz da medicina social está na medicina "clínica", e que aquela, ao olhar o processo histórico-social dos fenômenos em saúde-doença, deixa "de ser quase que apenas o conhecimento (biológico principalmente) das doenças e meios de curá-la e/ou a ciência do corpo biológico, normal e patológico" (Idem, p. 30).

Essa formulação ancora-se na discussão corrente à época sobre a relação individual-coletivo e as práticas de saúde. Isto é, não há doentes ou não doentes que ganhem expressão coletiva sem que tenham sido, em algum momento, reconhecidos como indivíduos clinicamente doentes, ou sãos, individualmente.

Pereira (2003) desenvolve sua crítica a esse objeto clínico, individual, biomédico - porque visto como portador de um excesso do componente biológico e da ausência de social. Para ele, a clínica enxerga o indivíduo apenas em sua face biológica e assim o manipula - específico, individualizado, relativo aos agentes etiológicos e/ou fatores causais das doenças -, em oposição aos contextos mais gerais, coletivos e sociais, determinantes do processo saúde-doença. Por isso mesmo, essa visão biológica de saúde seria um objeto suscetível à abordagem funcionalista, porque relativo à normalidade ou anomia que caracterizariam a dicotomia do indivíduo são ou doente. Para ele, uma mudança qualitativa de abordagem ocorreria quando esse objeto deixasse de representar apenas os 
corpos biológicos e fosse também representado por corpos sociais, coletivos. "Não se trata, tão somente, de indivíduos, mas de sujeitos sociais, de grupos e classes sociais e de relações sociais referidas ao processo saúde-doença” (Pereira, 1986, p. 30).

Esse "novo" objeto biossocial seria o da medicina social, na medida em que: "Realizada tal mudança, as práticas sociais da medicina e a saúde e a doença seriam objeto de investigação, especificamente, dessa disciplina social, que se poderia vincular à medicina desde que ela fosse concebida como uma ciência de um objeto social e natural ao mesmo tempo" (Idem, ibidem). Pereira entendia que os paradigmas da biologia em uso na medicina eram menos controvertidos que os das ciências sociais, nas quais inexiste um paradigma único. "A rotação de perspectivas quanto ao modo de encarar e interpretar esses objetos de estudo representa uma ruptura em relação à corrente positivista predominante. Tal rotação faz avançar a interpretação, introduzindo tipos diversos de explicação, sobretudo sociológica" (Idem, pp. 30-31).

Sua inovação guardou, porém, um paradoxo. Por um lado, reconhecia a natureza do indivíduo como ser social, inserido e pertencente a um coletivo - a classe social, os estratos sociais ou os grupos sociais -, o que resultava na compreensão de que a doença se manifestaria no que esse indivíduo representava ou expressava de social. Por outro lado, ele não procedeu a uma crítica teórico-epistemológica sobre a concepção do biológico em si, que é também, e sobretudo, produto social e cultural (Latour, 2004; Ianni, 2011a; 2011b).

Essa formulação sobre o social na saúde demarcará o debate da saúde coletiva no Brasil e o da medicina social na América Latina (Laurell, 1982), produzindo o conceito da determinação social do processo saúde-doença; daquela geração pioneira, apenas Laurel (1994) e Breilh (1994), no México e no Equador, retomarão posteriormente essa dicotomia, em uma releitura crítica do conceito de biológico.

A guinada em direção ao social descortinou para os críticos da biomedicina de então perspectivas de ampliação e sofisticação do objeto saúde, como a incorporação da complexidade histórico-social aos fenômenos de saúde-doença.

O processo saúde-doença tendeu, cada vez mais, a ser percebido como sendo determinado (em boa parte pelo menos) pelo funcionamento e dinâmica do sistema social inclusivo onde ele ocorre. Passaram a ser devidamente consideradas as diferenças sociais na produção dos ditos fenômenos. Percebeu-se que saúde e doença só são explicáveis quando a sociedade deixa de ser vista como um todo homogêneo, estável e a-histórico e passa a ser, ao contrário, visualizada como dividida em classes, estratos e grupos sociais, 
frequentemente opostos e mesmo antagônicos. Sob esse prisma, foram inovadas as concepções metodológicas que norteavam o entendimento de enfermidade. Ultrapassando relações causais imediatas, geralmente vinculadas apenas às características do organismo biologicamente considerado, a rotação de perspectivas permitiu chegar à noção de totalidade social (Pereira, 1986, pp. 35-36).

\section{A incorporação tecnológica na produção da saúde-doença}

Discutindo a sociologia nos horizontes das ciências sociais no Brasil, Martins (2010) menciona "novos" temas na área, entre eles ciência e tecnologia, e Baumgarten (2010, p. 442) diz que a sociologia tem abordado a ciência, a tecnologia e a inovação em uma perspectiva de realidades sombrias - considerada a vinculação da tecnociência ao capital -, alertando, porém, para os “extraordinários avanços no sentido da solução de carências humanas em áreas vitais como: a produção de alimentos, a medicina e a comunicação". Essa autora ressalta o caráter ambivalente da incorporação científico-tecnológica em virtude da melhoria da qualidade de vida, de um lado, e a restrição do acesso a bens, de outro.

Quando da constituição da saúde coletiva nos anos de 1970, foi de outra natureza a crítica que cientistas sociais da saúde estabeleceram sobre a medicina e sua intervenção técnica. Na perspectiva da análise da sua apropriação social, consideraram que, por ser uma intervenção técnica, a medicina - que se concebe como estritamente biológica - tem implicações políticas inegáveis, e que seria exatamente nessa mediação que a técnica médica atuaria.

Donnangelo discute a força de trabalho médico e o desenvolvimento científico tecnológico que ela realiza sob dois aspectos: a especialização e o desenvolvimento do trabalho sob a forma grupal, "características comuns à organização dos serviços de saúde nas sociedades que criaram ou incorporaram conhecimentos e técnicas médicas refinadas" (1975, p. 54).

Para ela, a especialização na medicina aparecia sob a forma de divisão técnica do trabalho, um resultado imediato da inovação técnico-científica. Essa especialização produziria uma diferenciação entre os profissionais médicos e seus instrumentos de trabalho, bem como - esta é uma das chaves de seu pensamento - uma diferenciação imediata do objeto do seu trabalho. Isto é, os doentes e suas patologias seriam cada vez mais diferenciados segundo as especializações médicas, por exemplo: quanto às fases do desenvolvimento biológico, geracional; quanto às patologias específicas; quanto às áreas e órgãos delimitados do corpo humano. Ou seja, a especialização tecnológica do 
trabalho médico arrastaria consigo a especialização/fragmentação dos corpos e suas enfermidades.

A outra face da incorporação científica-tecnológica ao trabalho médico seria o desenvolvimento do trabalho grupal, substituindo o trabalho individual do profissional liberal. Para Donnangelo, a complexidade das informações sobre as doenças e suas terapêuticas, a necessidade de introdução de novas técnicas diagnósticas e terapêuticas, a cooperação entre especialistas para realização diagnóstica e ação médica, o custo crescente dos equipamentos etc., levariam à concentração desses profissionais a um ambiente com alta incorporação tecnológica - o hospital -, alterando radicalmente as práticas de atenção à saúde.

Donnangelo e Pereira (1976) problematizam, ainda, a medicina em uma sociedade de classes, capitalista. Incorporando leituras de Foucault, pouco estudado pelas ciências sociais no Brasil nos anos de 1970, os autores afirmam que a função social do médico em limitar epidemias, controlar contágios e preservar populações inteiras é constitutiva da sociedade moderna, capitalista. Uma ação mediada pela "moderna medicina tecnológica [que] representa, antes de tudo, a mediação de um conjunto enorme de novos recursos de diagnóstico e terapêutica na relação entre o médico e o objeto do seu trabalho" (Donnangelo e Pereira, 1976, p. 20), e que se realizaria "no interior de um projeto que implica também a reestruturação da sociedade, com a depuração de todos os seus males" (Idem, p. 19); daí sua vocação intrinsecamente política.

Desdobrando seu argumento, assim como José Carlos Pereira (1986), Donnangelo e Luiz Pereira consideram a clínica médica especificidade do ato médico; ela seria o meio de trabalho do médico, por meio do qual se deveria suprimir a doença. Nesse contexto, o vasto conjunto de equipamentos materiais e os custos econômicos aí envolvidos, sua obsolescência e os meios de trabalho inovadores instauram entre o médico e o paciente um vínculo muito particular, que é o da medicina com os objetivos básicos da produção econômica, no caso, capitalista (Donnangelo e Pereira, 1976, p. 20). A relação médico-paciente, mediada pela técnica, é em si realização do processo produtivo capitalista.

[...] mediante a relação entre o trabalho médico e o objeto de tal prática, o desenvolvimento de tais recursos tecnológicos e de capital, equivale à possibilidade de uma radical transformação na produção de serviços, basicamente em dois sentidos: o da superação da clínica como meio básico de trabalho e o da absorção progressiva da medicina artesanal por novas modalidades de organização da produção (Idem, ibidem). 
Isso, dizem eles, politiza enormemente o ato médico, já que é impossível estabelecer um limite discernível entre o objeto do trabalho e seu produto, a saber, os corpos dos homens, enfermos. Na prática médica, o objeto de trabalho e o produto do trabalho são uma mesma coisa: o corpo humano.

Extremamente perspicaz, essa leitura antevia o esgotamento da clínica ação técnica - em substituição à inovação tecnológica incorporada ao trabalho médico por meio dos aparelhos diagnósticos e terapêuticos, em uma crescente separação entre o trabalhador médico e seus meios de trabalho, entre o médico e seu paciente; em termos marxistas, é possível dizer, uma crescente alienação do trabalho médico e, por decorrência, da saúde. É dessa forma que Donnagelo e Pereira (1976) desenvolvem sua análise radical da produção da saúde na sociedade contemporânea, trazendo o tema da incorporação científico-tecnológica ao cerne da questão. Mediada pela incorporação tecnológica, a clínica médica, "técnica", é atravessada pelos interesses econômicos, realizando o capital.

Há, ainda, outra face da medicina na sociedade de classes, segundo os autores. Como ciência do corpo, atribuindo-lhe a doença e definindo-a, a medicina transforma esse corpo em objeto suscetível de manipulação técnica, pois é "o reconhecimento daquelas regularidades cientificamente construídas [que] proporciona também o conceito referencial para elaboração dos conceitos de normal e patológico, inseparáveis da interferência técnica da medicina sobre o seu objeto" (Idem, p. 23). Na medida em que o corpo dos homens está inserido e em relação não só com o meio físico, mas com o social, sob formas históricas específicas, ele "se dimensiona e adquire significado por referência à especificidade da estrutura social” (Idem, p. 25), no caso a sociedade capitalista, de classes; um corpo disposto, antes de tudo, como agente de trabalho sobre o qual a medicina investe suas técnicas.

\section{Considerações finais}

Os contextos histórico-sociais diferenciados, a sobreposição por vezes conflituosa de referenciais teóricos e inserções institucionais dos sujeitos envolvidos, a renovação dos objetos das ciências naturais e sociais e as novas dinâmicas sociais contemporâneas são alguns dos elementos que fazem com que as contribuições teóricas do campo das ciências sociais em saúde estabelecidas nos anos de 1970 e 1980 só possam ser vistas em processo. Seria impossível proceder a um balanço exaustivo dessa contribuição teórica.

Não se pode celebrar e congelar o passado inconcluso que se reproduz nas mudanças em curso, presentes. É sabido, inclusive, que "os impasses, ou 
as tensões, que se verificam na produção do conhecimento na área [da saúde coletiva] em parte se devem àqueles da própria área das ciências sociais" (Cohn, 1992, p. 100). Também se deve reconhecer que as ciências sociais em saúde, essa pequena “constelação de ideias" (Brandão, 2005, p. 238), sofre continuidades e descontinuidades, reafirmação de tradições e rupturas.

A mudança radical entre o cenário político da época da estruturação desse campo e os dias de hoje é um fato, bem como as diferenças do debate naquela conjuntura da transição democrática para a conjuntura posterior, de consolidação democrática e de estruturação do Sistema Único de Saúde (Cohn, 1992; Augusto, 2000).

$\mathrm{Na}$ atualidade, o esforço teórico desenvolvido na gênese do campo se dissolveu produzindo efeitos ambivalentes. Houve ampliação e diversificação temática e de abordagens teórico-metodológicas, mas também houve rarefação teórica e crescente entonação aplicada.

O diálogo interdisciplinar, especialmente intenso na gênese do campo, se multiplicou e, paradoxalmente, se fragmentou, rarefez. Está hoje mais atinente às pesquisas empíricas do que ao debate teórico-epistemológico autocrítico inicial. Isso significa que o campo da Saúde Coletiva, hoje, adquire uma marca mais propositiva, prática e de caráter muitas vezes técnico, pragmático e aplicado. Tendência que reverbera na produção do conhecimento do campo como um todo e nas ciências sociais em saúde, também.

Nesse sentido, caracteriza-se como um campo reflexivo, nos termos de Giddens (1991), pois as formas do conhecimento sobre o processo social em saúde têm consequências práticas para a sociedade, práticas essas que são constantemente reexaminadas à luz das informações sobre elas produzidas.

\section{Referências bibliográficas}

Almeida, Lirane Elize Defane Ferreto de. (2011), Contribuição pra o estudo da comunidade cientifca da saúde coletiva: os grupos de pesquisa. Tese de doutorado. Campinas, Faculdade de Ciências Médicas/Unicamp.

AROUCA, Sérgio. (2003), O dilema preventivista: contribuição para a compreensão e crítica da medicina preventiva. São Paulo, Editora da Unesp.

SChwarCz, Lilia Moritz \& Botelho, André. (2011), "Simpósio: cinco questões sobre o pensamento social brasileiro”. Lua Nova, 82: 139-211.

Augusto, Maria Helena Oliva. (2000), "Reflexões sobre o uso de tecnologias médicas”. In: CANesQui, Ana Maria et al. (orgs.). Ciências sociais e saúde para o ensino médico. São Paulo, Hucitec/Fapesp. 
BASTIDE, Roger. (1967), Sociologia das doenças mentais. São Paulo, Companhia Editora Nacional.

Baumgarten, Maíra. (2010), "Pesquisa em ciência, tecnologia e inovação no Brasil”. In: Martins, Carlos Benedito \& Martins, Heloisa Helena T. de Souza (orgs.). Horizonte das ciências sociais no brasil: sociologia. São Paulo, Anpocs/Instituto Ciência Hoje/Barcarolla/Discurso Editorial.

Berlinguer, Giovanni et al. (1988). Reforma sanitária: Itália e Brasil. São Paulo, Hucitec/Cebes.

Bodstein, Regina Cele de A. (1992), "Ciências sociais e saúde coletiva: novas questões e novas abordagens”. Cadernos de Saúde Pública, 8 (2): 140-149.

Bourdieu, Pierre. (2013), "El campo científico”. Redes: Revista Hispana para el Análisis de Redes Sociales. Disponível em www.projetoprogredir.com.br/images/bibliografia-definitiva/01-02-13-biblio/epistemologia-y-educacion/yamila-gomez/yamilagomez-01/el-campo-cientifico-bourdieu.pdf, consultado em 6/12/2013.

BREILH, Jaime. (1994),“Las ciencias de la salud pública en la construcción de una prevención profunda: determinantes y proyecciones". In: RoDRIGUEZ, Maria Isabel (org.). Lo biológico y lo social: su articulación en la formación del personal de salud. Washington, Opas-OMS.

BRICEÑO-LEON, Roberto. (2003), "Las ciencias sociales y la salud: um diverso y mutante campo teórico”. Ciência \& Saúde Coletiva, 8 (1): 33-45.

BRANDÃo, Gildo Marçal. (2005), "Linhagens do pensamento político brasileiro". Dados: Revista de Ciências Sociais, 48 (2): 231-269.

CAMARGO JR., Kenneth Rochel de. (2003), Biomedicina, saber \& ciência; uma abordagem crítica. São Paulo, Hucitec.

CANESQUI, Ana Maria. (1995), Dilemas e desafios das ciências sociais na saúde coletiva. São Paulo, Hucitec/Abrasco.

. (1997), Ciências sociais e saúde. São Paulo, Hucitec/Abrasco. . (2007), Ciências sociais e saúde no Brasil. São Paulo, Hucitec.

. (2008), "As ciências sociais e humanas em saúde na Associação Brasileira de Pós-graduação em Saúde Coletiva”. Physis: Revista de Saúde Coletiva, 18 (2):215-250.

Cohn, Amélia. (1980), Previdência social e processo politico no Brasil. São Paulo, Moderna.

. (1992), "Conhecimento e prática em saúde coletiva: o desafio permanente". Saúde e Sociedade, 1 (2): 97-109.

Comissão Gulbenkian para a Reestruturação das Ciências Sociais. (1996), Para abrir as ciências sociais. São Paulo, Cortez.

Costa, Dina Czresnia et al. (1990), Epidemiologia: teoria e objeto. São Paulo, Hucitec/ Abrasco. 
Costa, Nilson do Rosário. (1992), "Ciências sociais e saúde: considerações sobre o nascimento do campo da saúde coletiva”. Saúde em Debate, 36: 58-65.

DeSLANDES, Suely Ferreira \& IRIART, Jorge Alberto Bernstein. (2012), “Usos teórico-metodológicos das pesquisas na área de ciências sociais e humanas em saúde”. Cadernos de Saúde Pública, 28 (12): 2380-2386.

Donnangelo, Maria Cecília Ferro. (1975), Medicina e sociedade: o médico e seu mercado de trabalho. São Paulo, Pioneira.

. (1983), “Apresentação”. In: NunES, Everardo Duarte (org.). Medicina social: aspectos históricos e teóricos. São Paulo, Global.

Donnangelo, Maria Cecília Ferro \& Pereira, Luiz. (1976), Saúde e sociedade. São Paulo, Duas Cidades.

ESCOREL, Sarah. (1999), Reviravolta na saúde: origem e articulação do movimento sanitário. Rio de Janeiro, Fiocruz.

FreYre, Gilberto. (2009), Sociologia da medicina. Recife, É Realizações.

GARCIA, Juan Cesar. (1985), “Educação médica”. In: NunEs, Everardo Duarte (org.). JCG: pensamento social em saúde na América Latina. São Paulo/Rio de Janeiro, Cortez/Abrasco.

Gerschman, Silvia. (1995), A democracia inconclusa: um estudo da reforma sanitária brasileira. Rio de Janeiro, Fiocruz.

Giddens, Anthony. (1991), As consequências da modernidade. São Paulo, Editora da Unesp.

Goldenberg, Paulete et al. (2003), O clássico e o novo: tendências, objetos e abordagens em ciências sociais e saúde. Rio de Janeiro, Fiocruz.

IANNI, Aurea Maria Zöllner. (2011a), “Questões contemporâneas sobre natureza e cultura: notas sobre a saúde coletiva e a sociologia no Brasil”. Saúde e Sociedade. São Paulo, 20 (1): 32-40.

. (2011b), "A saúde coletiva como campo científico e político na América Latina". In: Ferreira, Leila da Costa (org.). A questão ambiental na América Latina: teoria social e interdisciplinaridade. Campinas, Editora da Unicamp.

LATOur, Bruno. Politicas da natureza. Como fazer ciência na democracia. Trad. de Carlos Aurélio Mota de Souza. Bauru, SP, Edusc, 2004.

LAurell, Asa Cristina. (1982), "A saúde-doença como processo social”. Revista Latinoamericana de Salud, 2: 7-25.

. (1994), "Sobre la concepción Biológica y Social del Proceso Salud-Enfermedad". In: Rodriguez, Maria Isabel (org.). Lo biológico y lo social: su articulación en la formación del personal de salud. Washington, Opas-OMS.

LeAvell, H. \& ClaRK, E. G. (1965), Preventive medicine for the doctor in his community. Nova York, McGraw-Hill. 
Lessa, Renato. (2010), "O campo da ciência política no Brasil". In: Martins, Carlos Benedito \& Lessa, Renato (orgs.). Horizonte das ciências Sociais no Brasil Ciência Política. São Paulo, Anpocs/Instituto Ciência Hoje/Barcarolla/Discurso Editorial.

Loyola, Maria Andrea. (2012), “O lugar das ciências sociais na Saúde Coletiva”. Saúde e Sociedade, 21 (1): 9-14.

LuZ, Madel Therezinha. (1979), As instituiçôes médicas no Brasil: instituição e estratégia de hegemonia. Rio de Janeiro, Graal.

. (1982), Medicina e ordem politica brasileira: politicas e instituiçôes de saúde (1830-1930). Rio de Janeiro, Graal.

. (1988), Natural, racional, social: razão médica e racionalidade cientifica moderna. Rio de Janeiro, Campus.

Marsiglia, Regina Maria Giffoni et al. (2003), "Das ciências sociais em saúde: a produção científica de pós-graduação em ciências sociais”. Ciência \& Saúde Coletiva, 8 (1): 275-285.

Martins, Heloisa Helena T. de Souza. (2010), "A sociologia com campo científico". In: Martins, Carlos Benedito \& MArTins, Heloisa Helena T. de Souza (orgs.). Horizonte das ciências sociais no Brasil: sociologia. São Paulo, Anpocs/Instituto Ciência Hoje/Editora Barcarolla/Discurso Editorial.

MiCELI, Sergio. (1989), História das ciências sociais no Brasil. São Paulo, Vértice/Revista dos Tribunais/Idesp, vol. 1.

Minayo, Maria Cecília de Souza. (1994), O desafio do conhecimento:pesquisa qualitativa em saúde. São Paulo/Rio de Janeiro, Hucitec/Abrasco.

. (2013), "A produção de conhecimentos na interface entre as ciências sociais e humanas e a saúde coletiva”. Saúde e Sociedade, 22 (1), 21-31.

Minayo, Maria Cecília de Souza \& Coimbra Jr., Carlos Everardo A. (2005), Críticas e atuantes: ciências sociais e humanas em saúde na América Latina. Rio de Janeiro, Fiocruz.

NUNES, Everardo Duarte. (1985), “Tendências e perspectivas das pesquisas em ciências sociais na América Latina: uma visão geral”. In: NUNES, Everardo Duarte (org.). As ciências sociais em saúde na América Latina: tendências e perspectivas. Brasília, Opas-OMs.

. (1992). "As ciências sociais em saúde: reflexões sobre as origens e a construção de um campo de conhecimento". Saúde e Sociedade. São Paulo, 1 (1): 59-84.

. (1999), Sobre a sociologia da saúde. São Paulo, Hucitec.

. (2006), "A trajetória das ciências sociais em saúde na América Latina: revisão da produção científica”. Revista de Saúde Pública. São Paulo, 40: 64-72.

. (2014), "A sociologia da saúde no Brasil: a construção de uma identidade".

Ciência \& Saúde Coletiva, 19 (4): 1041-1052. 
NUNES, João Arriscado. (2005), "A pesquisa em saúde nas ciências sociais e humanas: tendências contemporâneas". Disponível em www.ces.uc.pt/publicacoes/oficina/ ficheiros/253.pdf, consultado em 30/6/2013.

Pereira, José Carlos de Medeiros. (1986), "Medicina, saúde e sociedade". Estudos de Saúde Coletiva, 4: 29-37.

(2003), Medicina, saúde e sociedade. Ribeirão Preto, Complexo Gráfico Villimpress.

ReIs, Elisa Pereira; ReIs, Fábio Wanderley \& Velho, Gilberto. (1997), "As ciências sociais nos últimos 20 anos: três perspectivas". Revista Brasileira de Ciências Sociais, 12 (35). Disponível em www.scielo.br/scielo.php?script=sci_arttext\&pid $=$ S0102-69091997000300002, consultado em 30/6/2013.

SARTI, Cynthia Andersen. (2010), "Saúde e sofrimento". In: MARTins, Carlos Benedito \& DUARTE, Luiz Fernando Dias (orgs.). Horizonte das ciências sociais no Brasil: antropologia. São Paulo, Anpocs/Instituto Ciência Hoje/Barcarolla/Discurso Editorial.

Tavares-dos-Santos, José Vicente \& Baumgarten, Maíra. (2005), “Contribuições da sociologia na América Latina à imaginação sociológica: análise, crítica e compromisso social". Sociologias, 7 (14): 178-243.

Teixeira, Sonia Fleury et al. (1995). Reforma sanitária: em busca de uma teoria. São Paulo, Cortez/Abrasco.

\section{Resumo}

O campo temático das ciências sociais em saúde no Brasil

O artigo apresenta o campo das ciências sociais em saúde, que integra o da saúde coletiva, no Brasil, consolidados na década de 1970. Discute alguns pressupostos sócio-históricos dessa constituição: a reestruturação do ensino médico e das pós-graduações nos anos de 1950 e 1960, que incorporaram as ciências sociais, e a inserção de cientistas sociais nos serviços de saúde no contexto de luta pela redemocratização nas décadas de 1970 e 1980. Problematiza o contato de cientistas sociais com a saúde, tomando-a como objeto, o que resulta na discussão de questões de cunho epistemológico pouco exploradas até então pelas ciências sociais no Brasil: as relações do biológico e do social e a mediação tecnológica na produção social da saúde-doença.

Palavras-chave: Saúde pública; Saúde coletiva; Ciências sociais em saúde; Biológico e social; Tecnologia e saúde.

\section{Abstract}

The thematic field of the social sciences in health in Brazil

The article presents the field of the social sciences in health, part of the field of collective health, consolidated in Brazil during the 1970s. It discusses some of the sociohistorical 
factors central to their constitution: the restructuring of medical teaching and postgraduate courses in the 1950s and 60s, incorporating the social sciences, and the insertion of social sciences in health services as part of the struggle to restore democracy in the country during the 1970s and 80s. The article problematizes the contact between social sciences and health, taking the latter as an object, which leads into a discussion of epistemological questions seldom explored by the social sciences in Brazil to date: the relations between the biological and the social, and technological mediation in the social production of health-sickness.

Keywords: Public health; Collective health; Social sciences in health; Biological and social; Technology and health.

\footnotetext{
D OI: http://dx.doi. org/10.1590/010320702015013.

Texto enviado em 29/1/2015 e aprovado em 13/3/2015.

Aurea Maria Zöllner Ianni é cientista social e professora doutora do Departamento de Prática de Saúde Pública da Faculdade de Saúde Pública da USP. E-mail: aureanni@usp.br.
}

32 Tempo Social, revista de sociologia da USP, v. 27, n. 1 